\title{
Wolbachia detection in insects through LAMP: loop mediated isothermal amplification
}

\author{
Daniela da Silva Gonçalves ${ }^{1}$, Anna Paula Alvim Cassimiro', Caroline Dantas de Oliveira', Nilton Barnabé Rodrigues ${ }^{2}$ \\ and Luciano Andrade Moreira ${ }^{1^{*}}$
}

\begin{abstract}
Background: The bacterium Wolbachia is a promising agent for the biological control of vector-borne diseases as some strains have the ability to block the transmission of key human disease-causing pathogens. Fast, accurate and inexpensive methods of differentiating between infected and uninfected insects will be of critical importance as field-based trials of Wolbachia-based bio-control become increasingly common.

Findings: We have developed a specific and sensitive method of detecting Wolbachia based on the isothermal DNA amplification. This technique can be performed in an ordinary heat block without the need for gel-based visualisation, and is effective for a wide variety of insect hosts.
\end{abstract}

Conclusion: Here we present the development of a rapid, highly sensitive and inexpensive method to detect Wolbachia in a variety of insect hosts, including key mosquito disease vectors.

Keywords: Wolbachia, LAMP-loop mediated isothermal amplification, Mosquito, Insect

\section{Findings}

Vector-borne diseases (e.g. malaria, dengue, filariases and Chagas disease) occur in more than 100 countries, primarily within the tropics, with the annual, global death rate in the millions. Despite the existence of a variety of vector control measures disease incidence is generally increasing, and consequently there is an urgent need to develop new and effective control strategies [1]. Ideally these strategies should be able to be used in conjunction with existing control methods, and in this context the bacterium Wolbachia pipientis has proven to be a promising alternative, given its ability to restrict pathogen development in many different mosquitopathogen combinations [2-5], and recently being applied in the field in Australia, Vietnam, Indonesia and soon in other dengue endemic countries (www.eliminatedengue.org).

Wolbachia is a vertically-transmitted bacterial endosymbiont of arthropods that is able to manipulate its host's reproductive system and consequently spread rapidly through wild populations [6]. Wolbachia was originally

\footnotetext{
*Correspondence: luciano@cpqrr.fiocruz.br

${ }^{1}$ Grupo: Mosquitos Vetores: Endossimbiontes e Interação Patógeno Vetor, Centro de Pesquisas René Rachou - Fundação Oswaldo Cruz, Av. Augusto de Lima 1715, 30190-002 Belo Horizonte, MG, Brazil

Full list of author information is available at the end of the article
}

identified in the ovaries of the mosquito Culex pipiens [7], and recent studies have estimated that $40 \%$ of terrestrial arthropod species are infected with the bacterium [8]. Critically, infections do not occur in key vector species including the dengue mosquito Aedes aegypti or in the Anopheles genus [9]. Wolbachia is typically detected within the host by PCR against genes such as wsp (Wolbachia surface protein) [10], ftsZ (cell division protein) [11], and $16 \mathrm{~S}$ ribosomal protein [12], or through fluorescence-based assays [13]. These techniques can be expensive to perform for large numbers of samples, and require the use of laboratory equipment.

The LAMP (loop mediated isothermal amplification) technique utilizes Bst DNA polymerase to create standdisplacement amplification, and operates at a constant temperature [14]. Examples of its use are very broad, ranging from the detection of pathogenic microorganisms to sex determination in embryos [15]. The LAMP product can be detected by the visualisation of turbidity, fluorescence or a metal ion indicator producing a colorimetric change [16] without the need to run a gel. These characteristics make LAMP a suitable method to detect Wolbachia under circumstances where minimum infrastructure is available. Here we report the use of LAMP to detect 
Wolbachia in a diverse range of insect species, which will prove beneficial to monitoring the progress of fieldbased trials utilising the bacterium.

\section{Methods}

We examined many different species including laboratoryreared mosquito lines of Aedes fluviatilis, naturally infected by the Wolbachia strain $w$ Flu, $A$. aegypti transinfected with the $w$ MelPop and $w$ Mel strains [17-19], and uninfected Anopheles aquasalis mosquitoes. These lines were reared at FIOCRUZ Minas as previously described [20]. We also examined field-captured mosquitoes including A. aegypti, A. albopictus, and Culex sp. Furthermore, insects belonging to a diverse range of orders, which were known to be Wolbachia-infected (unpublished results) were also included.

Specimens were stored in 96\% ethanol until DNA extraction. Whole insect specimens were homogenized for 1.5 min using a Mini-Beadbeater-16 (BioSpec), in $1.5 \mathrm{~mL}$ tubes containing one $3 \mathrm{~mm}$ glass bead and $80 \mu \mathrm{l}$ of homogenization buffer (10 mM Tris, $1 \mathrm{mM}$ EDTA, $50 \mathrm{mM} \mathrm{NaCl}[\mathrm{pH} 8.2])$, and were then centrifuged at $4^{\circ} \mathrm{C}$ for $30 \mathrm{~s}$ at $13,000 \mathrm{rpm}$ [21]. The samples were then incubated at $97^{\circ} \mathrm{C}$ for $10 \mathrm{~min}$, placed on ice for $15 \mathrm{~min}$, and centrifuged for $10 \mathrm{~min}\left(4^{\circ} \mathrm{C}, 13,000 \mathrm{rpm}\right)$. The supernatant was diluted 1:10. Primers for the Wolbachia 16S ribosomal sequence [12] were designed using the LAMP Designer 1.02 software (PREMIER Biosoft International) (Table 1).

Each LAMP reaction $\left(\mathrm{V}_{\text {total }}=25 \mu \mathrm{l}\right)$ contained $1 \times$ ThermoPol Reaction Buffer (20 mM Tris-HCl, pH 8.8, $10 \mathrm{mM} \mathrm{KCl}, 10 \mathrm{mM}\left(\mathrm{NH}_{4}\right)_{2} \mathrm{SO}_{4}, 2 \mathrm{mM} \mathrm{MgSO}, 0.1 \%$ Triton X-100), $0.32 \mathrm{mM}$ of each dNTP, $0.64 \mu \mathrm{M}$ of each internal primer (FIP/BIP), $0.32 \mu \mathrm{M}$ of LoopF and LoopB, $0.16 \mu \mathrm{M}$ of each external primer (F3/B3), 0.64 $\mathrm{M}$ of Betaine, $6 \mathrm{U}$ of Bst DNA polymerase, large fragment (New England Biolabs), and approximately $30 \mathrm{ng}$ of DNA. $1.2 \mathrm{mM}$ of the metal ion indicator Hydroxy Naphthol Blue (HNB) was added to the ThermoPol Reaction Buffer. The mixture was incubated at $63^{\circ} \mathrm{C}$ for 90 minutes on a thermocycler or heat block, to determine if the reaction

\begin{tabular}{|c|c|}
\hline Primer & Sequence $\left(5^{\prime}-3^{\prime}\right)$ \\
\hline F3 & CTCGTGTCGTGAGATGTTG \\
\hline B3 & GAACGTATTCACCGTGGC \\
\hline FIP & CCCACTCCATAAGGGCCATGAGGGACTITAAGGAAACTGCC \\
\hline BIP & CAATGGTGGCTACAATGGGCTGGCAGAGTACAATCCGAACTG \\
\hline LoopF & CCACCTTCCTCCAGTTTATCAC \\
\hline LoopB & CGCGAGGCTAAGCTAATCC \\
\hline
\end{tabular}

could be performed with a simpler setup. To check the sensitivity of the assay we cloned the external primer amplicon (F3/B3) into the pGemT-Easy (Promega) plasmid, and observed the efficacy of the assay on serial dilutions of the product.

\section{Results and discussion}

Loop mediated isothermal amplification has been used to detect different organisms, such as Leishmania [22], Toxoplasma gondii [23] and also bacteria belonging to the same class as Wolbachia (Alphaproteobacteria); Brucella spp [24], Anaplasma ovis [25] and Ehrlichia ruminantium [26]. We designed a LAMP-based assay to detect Wolbachia in different hosts using the bacterial $16 \mathrm{~S}$ rRNA sequence [12]. Initially we designed the four basic LAMP primers (F3, B3, FIP and BIP) but due to low specificity we then included the extra Loop primers [14].

To optimize the LAMP reaction for Wolbachia, samples of $A$. fluviatilis and wMel-infected $A$. aegypti were used to conduct a time course assay where we determined that

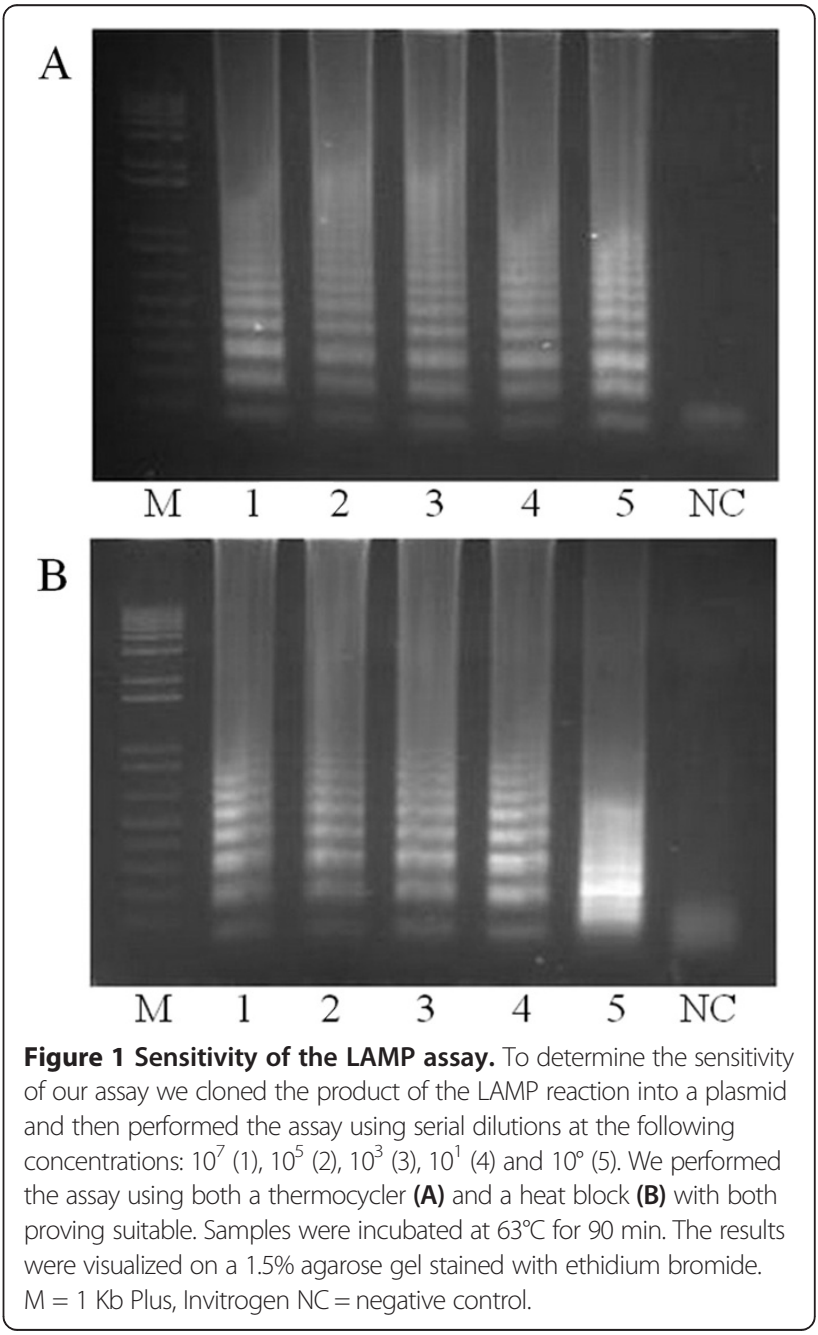


amplification first occurred after 60 minutes of incubation (at $63^{\circ} \mathrm{C}$ using a thermocycler - Additional file 1). This was subsequently standardized at 90 minutes in order to account for samples with low bacterial density.

Assay sensitivity was assessed by serially diluting plasmid DNA containing the target sequence. Dilutions containing $10^{7}, 10^{5}, 10^{3}, 10^{1}$ and $10^{\circ}$ copies of the target gene were incubated for $90 \mathrm{~min}$, using a thermocycler (Figure 1A) or heat block (Figure 1B). Sensitivity was high using either method, with amplification observed from as little as $10^{\circ}$ copies of the target sequence, although it should be noted that amplification from plasmids is more effective than from genomic DNA.

To check the specificity of our assay we analyzed mosquito specimens (Diptera: Culicidae) both infected and uninfected with Wolbachia. No amplification was observed in uninfected specimens, suggesting that the assay was highly specific and did not react to other bacteria infecting the mosquito gut [27]. We were also correctly able to identify Wolbachia infection in insect specimens from

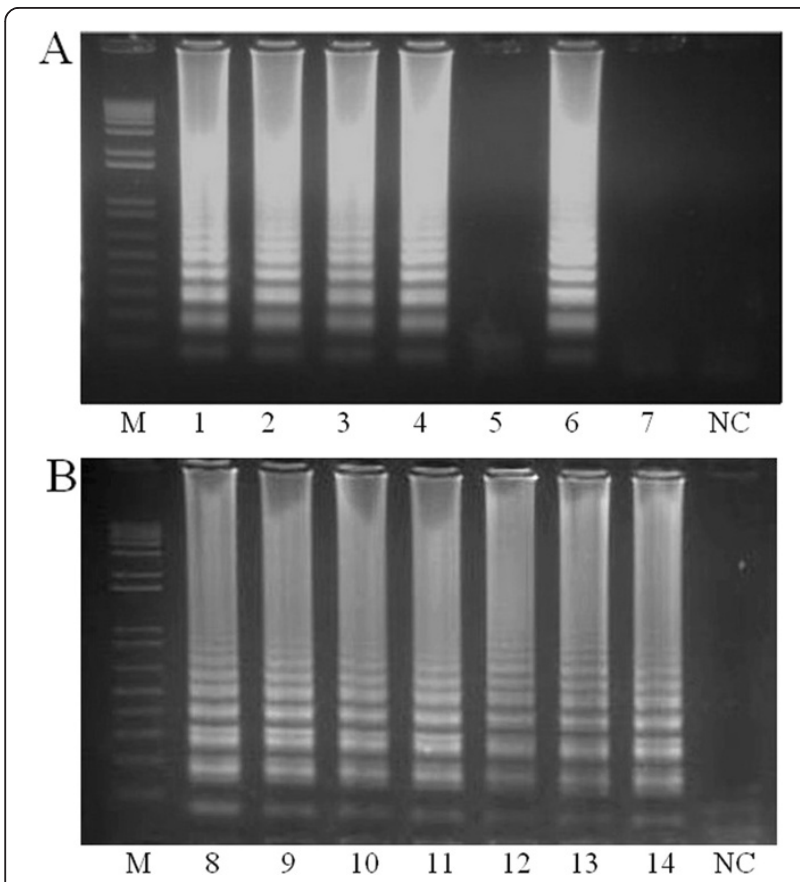

Figure 2 Specificity and reliability of the LAMP assay in different insects. To determine the specificity and reliability of our assay we amplified the DNA from different mosquito species (Diptera), including those naturally infected with Wolbachia: (A) Ae. albopictus (1), Ae. fluviatilis (2), Culex sp. (6) those with transinfections; Ae. aegypti - wMel (3), Ae aegypti - wMelPop (4), and those with no infection; Ae. aegypti (5), An. aquasalis (7). We also examined insects from a range of different orders that were known to be infected with Wolbachia: (B) Hymenoptera (8), Hemiptera (9), Lepidoptera (10), Orthoptera (11), Siphonaptera (12), Coleoptera (13), Isoptera (14). M = 1 Kb Plus, Invitrogen. NC= negative control. All Wolbachia-infected specimens amplified, while no amplification was observed for uninfected specimens indicating that the assay was both highly reliable and highly specific. other orders (Figure 2B). It is important to mention though, as lateral gene transfer events are quite common in Wolbachia [28] further confirmation of the presence of this bacterium (MLST strain typing or in situ hybridization for instance) will likely be appropriate in specific studies, where the high throughput screening for positive individuals is not the main objective.

The assay included the metal ion indicator Hydroxy Naphthol Blue [16] (which reacts with the pyrophosphate ion by-product of the reaction) to check whether we could detect Wolbachia without running agarose gels. We were able to clearly visualise a difference in colour after incubating the samples of A. fluviatilis (infected with $w$ Flu) and $A$ aegypti (wild type and infected with $w \mathrm{Mel}$ ), besides the negative $A$. aquasalis, for $150 \mathrm{~min}$ at $63^{\circ} \mathrm{C}$ in the thermocycler (Figure 3 ). This step could be utilized when access to laboratory equipment is limited and also has an advantage of reducing the risk of contamination (no need to open the tubes).

In terms of the cost per reaction, LAMP is approximately half as expensive as conventional PCR. If the cost of equipment is also included, LAMP becomes comparatively even cheaper given that it can be performed using only a heat block. As a further cost-saving measure, or if required in the field, homogenization of specimens could be performed using micro-pestles rather than a beadbeater.

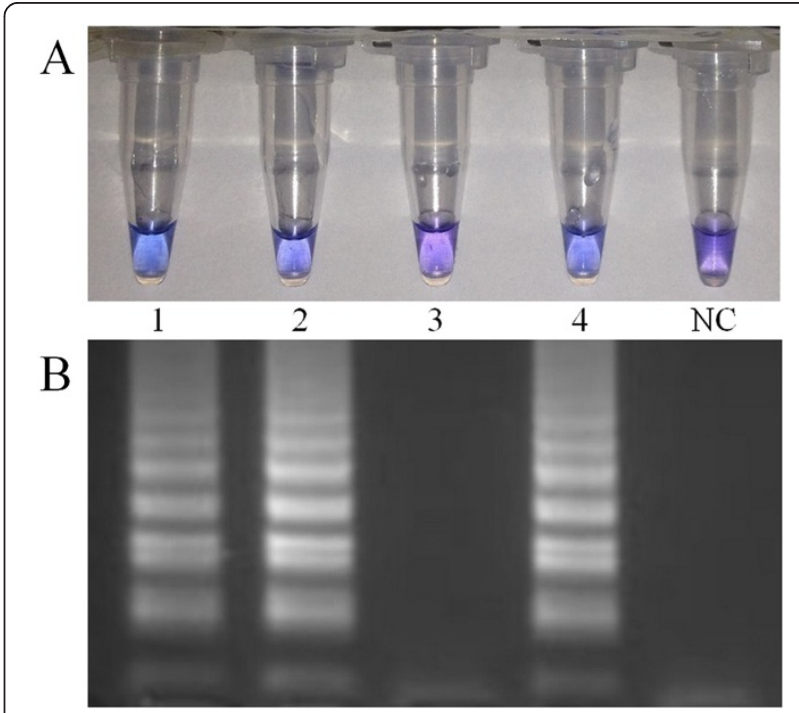

Figure 3 Detection of Wolbachia infection by ion indicator visualization. (A) With the addition of the ion indicator Hydroxy Naphtol Blue to the LAMP reaction it was possible to determine whether a mosquito specimen was Wolbachia-infected (blue), or -uninfected (purple) using the naked eye. The assay was highly specific with Wolbachia-infected Ae. fluviatilis (1), Culex spp. (2), Ae. aegypti (4), all giving a positive result, while the uninfected An. aquasalis (3) did not. (B) Ethidium bromide stained gel with (A) samples NC = negative control. 
We have demonstrated the reliability and sensitivity of using LAMP to detect Wolbachia, with detection possible for low-density infections, and the results easily visualized by the naked eye. Consequently, this technique could be readily applied in the field, without the need to use expensive laboratory equipment. This is the first report of the use of LAMP to detect Wolbachia infection in different hosts. The technique could potentially be applied to differentiating between multiple strains that could potentially occur within the same host species.

\section{Additional file}

Additional file 1: Standardization of the LAMP assay incubation time. To determine the optimal incubation time for the assay, LAMP reactions were performed using; (1) Ae. fluviatilis naturally infected with Wolbachia (wFlu), and (2) Ae. aegypti artificially infected with wMel. Samples were incubated at $63^{\circ} \mathrm{C}$ in a thermocycler and the tubes were removed at different times: $30 \mathrm{~min}$ (a), $60 \mathrm{~min}$ (b), $90 \mathrm{~min}$ (c), $120 \mathrm{~min}$ (d), $150 \mathrm{~min}$ (e). The products were visualised on a $1.5 \%$ agarose gel stained with EtBr. Visible products were present after 60 minutes of incubation. $\mathrm{NC}=$ negative control.

\section{Competing interests}

The authors declare that they have no competing interests.

\section{Authors' contributions}

DSG participated in the design of the study, carried out all experiments and drafted the manuscript. APAC helped to conduct the experiments. CDO collected and screened infected insects. NBR and LAM participated on the study design. LAM coordinated the work, critically reviewed the manuscript and contributed to obtaining the results. All authors read and approved the final version of the manuscript.

\section{Acknowledgements}

We thank Constancia Ayres for providing mosquito samples. We are in debt to Fernanda Rezende for technical and Alice Guimarães for administrative support, as well as Eric P. Caragata for critical reading. DS Gonçalves and LA Moreira are CNPq fellows. NBR is a CAPES fellow (BEX 11603/13-5).

\section{Financial support}

This work was supported by FAPEMIG, CNPq, the Brazilian Ministry of Health (DECIT/SVS), and a grant to Monash University from the Foundations for the National Institutes of Health through the Vector-Based Transmission of Control: Discovery Research (VCTR) program of the Grand Challenges in Global Health Initiatives of the Bill and Melinda Gates Foundations.

\section{Author details}

'Grupo: Mosquitos Vetores: Endossimbiontes e Interação Patógeno Vetor, Centro de Pesquisas René Rachou - Fundação Oswaldo Cruz, Av. Augusto de Lima 1715, 30190-002 Belo Horizonte, MG, Brazil. Entomologia Médica, Centro de Pesquisas René Rachou - Fundação Oswaldo Cruz, Av. Augusto de Lima 1715, 30190-002 Belo Horizonte, MG, Brazil.

Received: 25 March 2014 Accepted: 6 May 2014

Published: 19 May 2014

\section{References}

1. McGraw EA, O'Neill SL: Beyond insecticides: new thinking on an ancient problem. Nat Rev Microbiol 2013, 11:181-193.

2. Kambris Z, Cook PE, Phuc HK, Sinkins SP: Immune activation by life-shortening Wolbachia and reduced filarial competence in mosquitoes. Science 2009, 326(80):134-136.

3. Bian G, XU Y, Lu P, Xie Y, Xi Z: The Endosymbiotic Bacterium Wolbachia induces resistance to Dengue Virus in Aedes aegypti. PLoS Pathog 2010, 6:e1000833.
4. Glaser RL, Meola MAC-P: The native Wolbachia endosymbionts of Drosophila melanogaster and Culex quinquefasciatus increase host resistance to West Nile virus infection. PLoS One 2010, 5:e11977.

5. Bian G, Joshi D, Dong Y, Lu P, Zhou G, Pan X, Xu Y, Dimopoulos G, Xi Z: Wolbachia invades Anopheles stephensi populations and induces refractoriness to Plasmodium infection. Science 2013, 340(80-):748-751.

6. Werren JH, Baldo L, Clark ME: Wolbachia: master manipulators of invertebrate biology. Nat Rev Microbiol 2008, 6:741-751.

7. Hertig M, Wolbach SB: Studies on Rickettsia-like micro-organisms in insects *. J Med Res 1924, 44:329-374.7.

8. Zug R, Hammerstein P: Still a host of hosts for Wolbachia: analysis of recent data suggests that $40 \%$ of terrestrial arthropod species are infected. PLoS One 2012, 7:e38544.

9. Kittayapong P, Baisley KJ, Baimai V, O'Neill SL: Distribution and diversity of Wolbachia infections in Southeast Asian mosquitoes (Diptera: Culicidae). J Med Entomol 2000, 37:340-345.

10. Zhou W, Rousset F, O'Neil S: Phylogeny and PCR-based classification of Wolbachia strains using wsp gene sequences. Proc Biol Sci 1998, 265:509-515.

11. Werren JH, Zhang W, Guo LR: Evolution and phylogeny of Wolbachia: reproductive parasites of arthropods. Proc Biol Sci 1995, 261:55-63.

12. Simoes P, Mialdea G, Reiss D, Sagot F, Charlat S: Wolbachia detection: an assessment of standard PCR Protocols. Mol Ecol Resour 2011, 11:567-572

13. Casper-Lindley C, Kimura S, Saxton DS, Essaw Y, Simpson I, Tan V, Sullivan W: Rapid fluorescence-based screening for Wolbachia endosymbionts in Drosophila germ line and somatic tissues. Appl Environ Microbiol 2011, 77:4788-4794.

14. Notomi T, Okayama H, Masubuchi $H$, Yonekawa T, Watanabe $K$, Amino $N$, Hase T: Loop-mediated isothermal amplification of DNA. Nucleic Acids Res 2000, 28:e63.

15. Fu S, Qu G, Guo S, Ma L, Zhang N, Zhang S, Gao SSZ: Applications of loop-mediated isothermal DNA amplification. Appl Biochem Biotechnol 2011, 163:845-850.

16. Goto M, Honda E, Ogura A, Nomoto A, Hanaki K-l: Colorimetric detection of loop-mediated isothermal amplification reaction by using hydroxy naphthol blue. Biotechniques 2009, 46:167-172.

17. Moreira LA, Iturbe-Ormaetxe I, Jeffery JA, Lu G, Pyke AT, Hedges LM, Rocha BC, Hall-Mendelin S, Day A, Riegler M, Hugo LE, Johnson KN, Kay BH, McGraw EA, Van den Hurk AF, Ryan PA, O'Neill SL: A Wolbachia symbiont in Aedes aegypti limits infection with Dengue, Chikungunya, and Plasmodium. Cell 2009, 139:1268-1278.

18. McMeniman CJ, Lane AM, Fong AW, Voronin DA, Iturbe-Ormaetxe I, Yamada R, McGraw EA, O'Neill SL: Host adaptation of a Wolbachia strain after long-term serial passage in mosquito cell lines. Appl Env Microbiol 2008, 74:6963-6969

19. Walker T, Moreira LA: Can Wolbachia be used to control malaria? Mem Inst Oswaldo Cruz 2011, 106:212-217.

20. Baton LA, Pacidônio EC, Gonçalves DDS, Moreira LA: wFlu: characterization and evaluation of a native Wolbachia from the mosquito Aedes fluviatilis as a potential vector control agent. PLoS One 2013, 8:e59619.

21. Fu Y, Gavotte L, Mercer DR, Dobson SL: Artificial triple Wolbachia infection in Aedes albopictus yields a new pattern of unidirectional cytoplasmic incompatibility. Appl Environ Microbiol 2010, 76:5887-5891.

22. Khan MGM, Bhaskar KRH, Salam MA, Akther T, Pluschke G, Mondal D: Diagnostic accuracy of loop-mediated isothermal amplification (LAMP) for detection of Leishmania DNA in bufft coat from visceral leishmaniasis patients. Parasites \& Vectors 2012, 5:280.

23. Kong QM, Lu SH, Tong QB, Lou D, Chen R, Zheng B, Kumagai T, Wen LY, Ohta $\mathrm{N}$, Zhou XN: Loop-mediated isothermal amplification (LAMP): early detection of Toxoplasma gondii infection in mice. Parasites \& Vectors 2012, 5:2.

24. Song L, Li J, Hou S, Li X, Chen S: Establishment of loop-mediated isothermal amplification (LAMP) for rapid detection of Brucella spp. and application to milk and blood samples. J Microbiol Methods 2012, 90:292-297.

25. Ma M, Liu Z, Sun M, Yang J, Guan G, Li Y, Luo J, Yin H: Development and evaluation of a loop-mediated isothermal amplification method for rapid detection of Anaplasma ovis. J Clin Microbiol 2011, 49:2143-2146.

26. Nakao R, Stromdahl EY, Magona JW, Faburay B, Namangala B, Malele I, Inoue N, Geysen D, Kajino K, Jongejan F, Sugimoto C: Development of loop-mediated isothermal amplification (LAMP) assays for rapid detection of Ehrlichia ruminantium. BMC Microbiol 2010, 10:296. 
27. Minard G, Mavingui P, Moro CV: Diversity and function of bacterial microbiota in the mosquito holobiont. Parasit Vectors 2013, 6:146.

28. Dunning Hotopp JC, Clark ME, Oliveira DCSG, Foster JM, Fischer P, Muñoz Torres MC, Giebel JD, Kumar N, Ishmael N, Wang S, Ingram J, Nene RV,

Shepard J, Tomkins J, Richards S, Spiro DJ, Ghedin E, Slatko BE, Tettelin H,

Werren JH: Widespread lateral gene transfer from intracellular bacteria to multicellular eukaryotes. Science 2007, 317:1753-1756.

doi:10.1186/1756-3305-7-228

Cite this article as: Gonçalves et al.: Wolbachia detection in insects

through LAMP: loop mediated isothermal amplification. Parasites \& Vectors 2014 7:228.

\section{Submit your next manuscript to BioMed Central and take full advantage of:}

- Convenient online submission

- Thorough peer review

- No space constraints or color figure charges

- Immediate publication on acceptance

- Inclusion in PubMed, CAS, Scopus and Google Scholar

- Research which is freely available for redistribution 